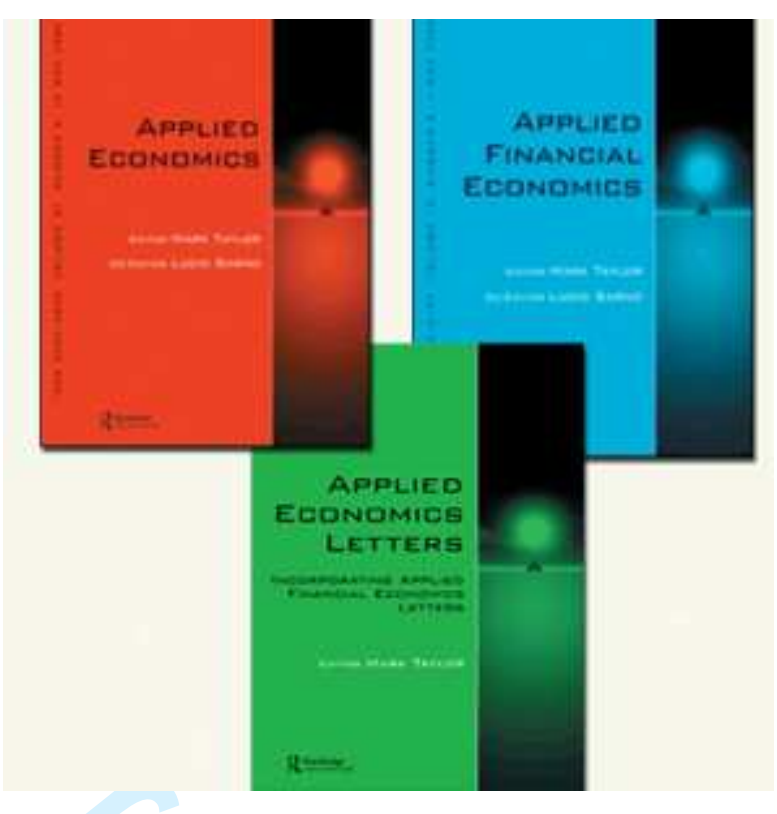

\title{
Gambling and credit: an individual and household level analysis for the UK
}

\begin{tabular}{|c|c|}
\hline Journal: & Applied Economics \\
\hline Manuscript ID: & APE-2011-0096.R1 \\
\hline Journal Selection: & Applied Economics \\
\hline $\begin{array}{r}\text { Date Submitted by the } \\
\text { Author: }\end{array}$ & 18-May-2011 \\
\hline Complete List of Authors: & $\begin{array}{l}\text { Brown, Sarah; University of Sheffield, Economics } \\
\text { Dickerson, Andy; University of Sheffield, Economics } \\
\text { mchardy, Jolian; University of Sheffield, Economics } \\
\text { Taylor, Karl; University of Sheffield, Economics }\end{array}$ \\
\hline JEL Code: & $\begin{array}{l}\text { D14 - Personal Finance }<\text { D1 - Household Behavior and Family } \\
\text { Economics }<\text { D - Microeconomics, D81 - Criteria for Decision- } \\
\text { Making under Risk and Uncertainty }<\text { D8 - Information and } \\
\text { Uncertainty }<\text { D - Microeconomics, L83 - } \\
\text { Sports } \mid \text { Gambling|Recreation|Tourism }<\text { L8 - Industry Studies: } \\
\text { Services }<\text { L - Industrial Organization }\end{array}$ \\
\hline Keywords: & Risk-taking, Gambling, Credit, Debt \\
\hline
\end{tabular}




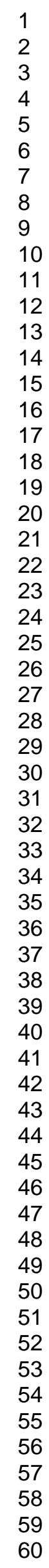

\section{SCHOLARONE ${ }^{m}$ \\ Manuscripts}

7

25

26

27

29

30

32

33

34

35

36

37

39

40

41

42

44

45

46

47

48

49

51

52

53

54

56

57

58

60

Editorial Office, Dept of Economics, Warwick University, Coventry CV4 7AL, UK 


\title{
Gambling and credit: an individual and household level analysis for the UK
}

\author{
S. Brown ${ }^{\mathrm{a}}$, A. Dickerson ${ }^{\mathrm{a}}$, J. McHardy ${ }^{\mathrm{a},{ }^{*}}$ and K. Taylor ${ }^{\mathrm{a}}$ \\ ${ }^{a}$ Department of Economics, University of Sheffield, 9 Mappin Street, Sheffield, UK, S1 4DT \\ * Corresponding author. E-mail: j.mchardy@shef.ac.uk
}

\begin{abstract}
We explore the relationship between gambling and the use of credit at the individual and household levels using representative pooled cross-section data from the UK Expenditure and Food Surveys (2001-2007). Gambling and the use of credit are shown to be positively correlated at the household level. We find that both the incidence and amount of gambling vary according to household income and the positive association between gambling and credit is stable across household income. It is also apparent that there is strong intra-household correlation in both gambling activity and the use of credit, with stronger relationships in lower income households.
\end{abstract}

Key Words: Risk-taking, Gambling, Credit, Debt

JEL Classification: D14, D81, L83 


\section{Introduction and Background}

According to the 2007 British Gambling Prevalence Survey (Wardle et al., 2007) gambling activity in the UK is widespread, with almost $70 \%$ of the population claiming to have taken part in some form of gambling in the previous 12 months. Although the National Lottery was found to be the most popular form of gambling activity, almost half of the population had engaged in at least one other form of gambling. Gambling expenditure in Britain has also been increasing rapidly in recent years; turnover in the gambling industry was $£ 84$ billion in $2006 / 07$ compared to just $£ 53$ billion in $2003 / 04$, (Gambling Commission, 2008), during a period in which progressive liberalisation, deregulation and innovation in the industry have stimulated new forms of gambling (e.g. spread-betting and online gambling) and raised its availability and accessibility. ${ }^{1}$

Somewhat surprisingly, there has been relatively little systematic, detailed research on the determinants of gambling and its association with other forms of risk-taking behaviour by individuals or households. This paper aims to contribute to our understanding of these important issues. In particular, we explore the relationship between gambling and the use of credit at the household level in order to place gambling activity within the wider context of household finances and financial risktaking (see also Wärneryd, 1996; Tokunaga, 1993; Ida and Goto, 2009; and Fellner and Maciejovsky, 2007). Given the rapid expansion in the use of credit over the past decade and the potential financial vulnerability that debt can engender, we examine this relationship across different levels of household income. In addition, to further our understanding of gambling and debt at the household level, we also explore the prevalence of intra-household gambling in order to investigate the extent to which gambling activity is correlated across household members.

A number of studies have identified specific socio-economic groups as being at increased risk from gambling, including the less-educated and those with low income (e.g. Shepherd et al., 1998), some ethnic minorities (e.g. Welte et al., 2001) and youths (e.g. Stinchfield and Winters, 1998). The

\footnotetext{
${ }^{1}$ The 2005 Gambling Act came into effect on 1 September 2007, replacing the Betting, Gaming and Lotteries Act 1963, the Gaming Act 1968 and the Lotteries and Amusements Act 1976. While the new act tightened some regulations relating to gambling activity, it also brought about a significant relaxation in some other areas of regulation (e.g. by allowing TV and radio advertising of gambling along with permitting more regional casinos and bigger slot machine payouts).
} 
statistical summaries by Sproston et al. (2000) and Wardle et al. (2007) of the two British Gambling Prevalence Surveys also report activity varying noticeably by education, income, ethnicity and age, but also by gender, economic activity and social group. Moreover, Clotfelter and Cook (1989) find that gambling acts as a regressive tax on the poor, adding to pre-existing socio-economic inequalities.

Within the wider context of household finances, there has been a significant increase in consumer debt in the UK over the last decade or so, as well as a rapid increase in gambling expenditure. According to May et al. (2004), total lending to the UK household sector has recently been growing faster than household income, and the latest (January 2010) Bank of England statistics reveal that total UK personal debt at the end of November 2009 stood at $£ 1.46$ trillion. $^{2}$ Despite Government concern over debt accumulation, there is a relative scarcity of research into the determinants of debt at the household level. ${ }^{3}$ However, some existing studies have identified an association between financial insecurity and gambling. For instance, according to Fisher (1996), in a study of British casino gambling, over half of problem gamblers had been forced to turn to others for financial support, and approaching a half had been forced to sell possessions to service their gambling debts. There has been some interest in establishing the costs and benefits of gambling, where indebtedness has been highlighted as a potential financial cost. For example, a NORC (1999) report ${ }^{4}$ indicated a rate of bankruptcy amongst pathological gamblers in the US to be approximately four times higher than for 'low risk' gamblers (5\%) and non-gamblers (4\%). This is consistent with the findings of the National Gambling Impact Study Commission (1999) which reported bankruptcy rates in the US amongst Gamblers Anonymous members to be around 20\%. Furthermore, according to the GamCare Services Report (2003), the average unsecured debt of gamblers receiving treatment from GamCare in the UK was just under $£ 30,000$ in 2003 . Nevertheless, there has been relatively little

\footnotetext{
2 This is now at a level in excess of UK annual GDP and, while the majority (85\%) of UK personal debt is secured on property, just how secure this is given the volatility in the housing market in the UK in recent years is an open question.

${ }_{3}^{3}$ Recent contributions in this area have been made by Brown et al. (2008) and Brown and Taylor (2008) focusing on financial expectations and financial pressure at the household level.

${ }^{4}$ National Opinion Research Centre (NORC) at the University of Chicago.
} 


\section{Data and Methodology}

\section{Data}

Our data are drawn from the UK Expenditure and Food Survey (EFS), 2001-2007, which is compiled by the ONS and DEFRA. This is an annual cross-section survey of around 6,000 households per year comprising around 15,000 individuals (adults and children). The EFS resulted from a merger of the Family Expenditure Survey (FES) and the National Food Survey (NFS) in 2001/2. ${ }^{5}$ Originally constructed on a financial year basis, it moved to a calendar year basis from January 2006 to be consistent with other major ONS surveys. The EFS is used to provide information for the construction of the UK retail price index (RPI) as well as in estimating consumption expenditures for the National Accounts. $^{6}$

\footnotetext{
${ }^{5}$ There were a number of significant changes when the FES and NFS were merged into the EFS, and so we do not attempt to utilise data prior to 2001.

${ }^{6}$ Note that while the EFS is ostensibly a household survey, we also have access to the individual expenditure diaries so can make use of the survey data at the individual level as well as at the more aggregated household level.
} 
We pool data from seven EFS surveys (2001/2, 2002/3, 2003/4, 2004/5, 2005/6, 2006, and 2007), taking care not to include the repeated observations in the first quarter of 2006 when the survey switched from financial to calendar years. There are three main elements to the EFS data collection. First, there is the household questionnaire which gathers key information and characteristics about the household, and is usually completed by the household reference person (i.e. the head of household). Second, there is an income questionnaire which records the key person-level information. Finally, there is the expenditure and food diary which each individual respondent completes every day for a two week period, and which records every single item of expenditure made by each separate individual member of the household.

We utilise data from all three elements of the EFS in the analysis undertaken below. Individuals' gambling expenditures are derived from their individual diary data, and are then merged with their individual and household characteristics drawn from the income and household questionnaires, respectively. ${ }^{7}$ Finally, data on individuals' loans and other forms of credit are merged with their gambling expenditures and other characteristics. Where these are not already derived variables provided within the EFS data, household level variables are constructed by aggregating across all household members. The accounting period for all EFS derived variables is on a (averaged) weekly basis, and so the information taken from the two-week diary data is also averaged correspondingly. The EFS is a stratified random sample with clustering, and weights are required in order to ensure that the resulting statistics are representative of the UK population. These weights are employed as appropriate in the analysis undertaken below. All monetary values are deflated to 2005 prices using the monthly RPI index (CHAW, rebased to average $2005=100)$ corresponding to the respondent's month of interview.

Total gambling expenditure is the sum of the stakes placed on a variety of gambling activities, including: football 'pools', bingo, book-makers, lottery (including National Lottery, Irish and other lotteries) and scratch cards. While we note the potential difficulties in collecting data on gambling

\footnotetext{
${ }^{7}$ Of course, we recognise that there may be underreporting of gambling activity in the EFS in the same way as alcohol and tobacco consumption are known to be underreported in household surveys of this kind. However, the large number of other control variables we include in our analysis should hopefully remove the influence of any systematic underreporting between different groups within the population.
} 


\section{Methodology}

In the empirical analysis below, estimation is undertaken separately at three different levels of aggregation: (1) at the household level; (2) for heads of households; and (3) at the individual level for all adults while allowing for intra-household correlation in gambling. We pool the data across the seven EFS surveys, but the unit of observation differs across the three specifications.

\footnotetext{
${ }^{8}$ This compares quite closely to Wardle et al. (2007, p.31) who report that $41 \%$ of adults said they participated in gambling in the last week.
} 
Initially, we investigate which characteristics at the household and head of household level are associated with the probability of gambling. Defining $G_{h t}^{*}$ as a continuous latent variable ('gambling propensity') and its observed empirical counterpart as $G_{h t}$, then:

$$
G_{h t}=\left\{\begin{array}{cc}
1 & \text { if } G_{h t}^{*}=\gamma_{1} R_{h t}+\beta_{1}{ }^{\prime} \mathbf{X}_{h t}+u_{h t}>0 \\
0 & \text { otherwise }
\end{array}\right.
$$

determines if the unit of observation $h$ (household or head of household), pooled over time $t$, places a stake on any type of gambling activity. With normality assumptions on the error term, $u_{h t}$, Equation 1a is estimated via a probit specification. $R_{h t}$ is a binary indicator for whether any credit repayments were made, where the key parameter of interest is $\gamma_{1}$, which serves to inform us about the relationship between the probability of gambling and the use of credit. Additional covariates are specified in the vector $\mathbf{X}_{h t}$ and are defined below.

For the third specification based on adult individuals, we define $G_{i h t}^{*}$ as a continuous latent variable ('gambling propensity') and its observed empirical counterpart as $G_{i h t}$, with:

$$
G_{i h t}=\left\{\begin{array}{cc}
1 & \text { if } G_{i h t}^{*}=\gamma_{2} R_{i h t}+\beta_{2}^{\prime} \mathbf{X}_{i h t}+\varepsilon_{i h t}>0 \\
0 & \text { otherwise }
\end{array}\right.
$$

if the unit of observation (adult individuals $i$ within a household $h$, pooled over time $t$ ), places a stake on any type of gambling activity. In Equation $1 \mathrm{~b}$ the error term is decomposed (ignoring time subscripts) as $\varepsilon_{i h}=\alpha_{h}+\eta_{i h}$ where $\alpha_{h}$ represents the household-specific unobservable effect and $\eta_{i h}$ is a random error term, $\eta_{i h} \sim N\left(0, \sigma_{\eta i h}^{2}\right)$. Hence, the correlation between the error terms of individuals within households is a constant given by: $\rho_{1}=\operatorname{corr}\left(\varepsilon_{l h}, \varepsilon_{k h}\right)=\sigma_{\alpha h}^{2} /\left(\sigma_{\alpha h}^{2}+\sigma_{\eta i h}^{2}\right),(l \neq k)$ where $\rho_{1}$ represents the proportion of the total unexplained variance in the dependent variable contributed by the household variance component. Thus, the magnitude of $\rho_{1}$ yields information pertaining to the incidence of intra-household gambling.

Having examined whether an association exists between credit payments and the probability of gambling at the three levels of aggregation, specifications are also estimated to investigate whether the covariates also influence the amount of the stake placed. Given that the gambling stake, $S$, cannot be 
negative, it is treated as a censored variable in our econometric analysis. Since the distribution of the weekly stake is highly skewed, we specify a logarithmic dependent variable following Gropp et al. (1997). For units of observation (i.e. households, head of households, or individuals) reporting zero gambling stakes, $\ln (S)$ is recoded to zero, as there are no reported stakes between zero and unity. We employ a tobit specification to identify the determinants of $\ln (S)$ which allows for the censored dependent variable.

We estimate the following pooled tobit model at the household and head of household level, $h$, for gambling expenditure:

$$
\begin{aligned}
& \ln \left(S_{h t}^{*}\right)=\theta_{1} \ln \left(C_{h t}\right)+\pi_{1}{ }^{\prime} \mathbf{X}_{h t}+w_{h t} \\
& \ln \left(S_{h t}\right)=\ln \left(S_{h t}^{*}\right) \quad \text { if } \quad S_{h t}^{*}>0 \\
& \ln \left(S_{h t}\right)=0 \quad \text { otherwise }
\end{aligned}
$$

where $S_{h t}$ is the stake placed by the household or head of household $h$ at time $t, C_{h t}$ is the total credit repayments of the household, and $w_{h t}$ denotes a stochastic disturbance term, $w_{h t} \sim N\left(0, \sigma_{w h t}^{2}\right)$. The key parameter of interest is $\theta_{1}$ which serves to inform us about the relationship between the level of gambling stakes placed and the amount of credit repayments. When estimating over all adult individuals:

$$
\begin{aligned}
& \ln \left(S_{i h t}^{*}\right)=\theta_{2} \ln \left(C_{i h t}\right)+\pi_{2}{ }^{\prime} \mathbf{X}_{i h t}+v_{i h t} \\
& \ln \left(S_{i h t}\right)=\ln \left(S_{i h t}^{*}\right) \quad \text { if } \quad S_{i h t}^{*}>0 \\
& \ln \left(S_{i h t}\right)=0 \quad \text { otherwise }
\end{aligned}
$$

where $S_{i h t}$ is the stake placed by individual $i$ in household $h$ at time $t, C_{i h t}$ is the total credit repayments of the individual, the error term is once again decomposed (ignoring time subscripts) in the same manner as previously, $v_{i h}=\varphi_{h}+\psi_{i h}$, such that $\rho_{2}=\operatorname{corr}\left(v_{l h}, v_{k h}\right)=\sigma_{\varphi h}^{2} /\left(\sigma_{\varphi h}^{2}+\sigma_{\psi i h}^{2}\right)$, $(l \neq k)$ where $\rho_{2}$, represents the proportion of the total unexplained variance in the dependent variable contributed by the household variance component. Thus, the magnitude of $\rho_{2}$ yields information pertaining to the levels of intra-household gambling. 
In our set of covariates, $\mathbf{X}$, in the probit and tobit specifications, controls are included for a number of influences which may affect either the probability of engaging in gambling activity or the level of gambling expenditure. For the models which focus upon household level or head of household analysis, covariates in $\mathbf{X}$ are specified for the head of household where appropriate (e.g. gender), whilst, for the individual level analysis, covariates in $\mathbf{X}$ are defined at the individual level, with the exception of the household level characteristics. To be specific, we control for the following characteristics: gender; a quadratic in age; ethnicity (only available for the head of household); age left full time education (FTE); being a lone parent; and marital status, i.e. whether cohabiting, single, widowed, separated or divorced. Controls for labour force status are also included: whether full-time employed; part-time employed; unemployed or not in the labour market. Household characteristics include: housing tenure, i.e. whether the accommodation is rented privately, owned on a mortgage or owned outright, and log (real) weekly household income. We also condition upon year and regional dummy variables.

\section{Results}

The probability of gambling and the use of credit

We first present the results where Equations $1 \mathrm{a}$ and $1 \mathrm{~b}$ are estimated via a probit specification to investigate whether there is any association between those households and individuals who have to make any regular credit repayments, and the probability of gambling. The results are shown in Specification A of Table 1 where the analysis is conducted at the household level (Panel 1), head of household level (Panel 2) and individual level (Panel 3). Marginal effects on the probability of gambling are reported in each case. It is apparent that, across all three levels of aggregation, the influence of whether a household or individual makes any weekly credit repayment on the probability of gambling is positive and statistically significant, and also very similar for all three levels of aggregation. Thus, for example, focussing on households (Panel 1), making current credit repayments is associated with a 5 percentage point higher probability of gambling. This effect is large as compared to the mean (the mean probabilities of gambling are: $54 \%$ at the household level; $41 \%$ for the head of household; and $39 \%$ at the individual level). 
Other findings common across the different levels of aggregation, and which are consistent with the existing empirical evidence (see, for example, Sproston et al., 2000; Wardle et al., 2007), are that males and lone parents are more likely to gamble. The probability of gambling is also increasing in age, albeit at a decreasing rate and reaching a peak at around age 55. Factors that lower the probability of gambling are the number of years of education, being non-white, all labour market states relative to being in paid employment, a higher number of children in the household, and housing tenure relative to living in accommodation owned by a local authority (LA) or housing association (HA). The association of gambling with household income is insignificantly different from zero at the mean household income, ceteris paribus, for both households (Panel 1), and for head of households (Panel 2). However, at the individual level (as reported in Panel 3), the relationship between gambling and income is more complex - higher household income is associated with significantly lower individual gambling propensity, although this effect is offset to a degree by higher individual income. We explore this in greater detail in Section IV below.

The final column in Table 1 which presents the individual level analysis, allows for intrahousehold correlation in gambling propensity. This appears to be important since the estimated correlation coefficient $\rho_{1}=0.2441$ is positive and statistically significant. Hence around one quarter of the unexplained variation in individuals' gambling propensity can be accounted for by the (unobserved) predilection of others in the household to engage in gambling.

In order to explore whether gambling is associated with particular types of credit, the dummy variable indicating whether any credit repayments are currently being made is decomposed into three types: loans; hire purchase (HP) agreements; and credit clubs. Individuals and households may have more than one type of credit. Making payments on loans is by far the most common form of credit repayment (being a factor of between 5 and 10 times the size of mean HP payments, which are again roughly twice the size of credit club repayments). The results obtained for the different types of credit are reported in Specification B of Table 1 (the other covariates in Specification A are also included in these regressions but are not reported since their marginal effects are little changed). It is apparent that the existence of credit club repayments is most strongly associated with the probability of gambling, with an 8.5 percentage point increase in the probability of gambling at the household level and a 9.5 
percentage point increase in the probability of gambling for individuals when this form of credit is utilised. However, relatively few households or individuals access this form of credit. In contrast, households and individuals with HP agreements are no more or less likely to gamble than those without this form of credit. ${ }^{9}$

\section{The level of gambling expenditure and the amount of credit repayments}

Specification A of Table 2 presents the results from the tobit analysis, where we investigate the relationship between the amount of current credit repayments and the amount of the gambling stakes. To evaluate the impact of a covariate on the level of gambling expenditure, we derive the marginal effects for the censored variable from the estimated coefficients. These are calculated by multiplying the estimated coefficient, $\theta$, by the scaling factor (ignoring subscripts): $\phi\left(\left\{\theta \ln (C)+\pi^{\prime} \mathbf{X}\right\} / \sigma\right)$, where $\phi$ denotes the cumulative distribution of the standard normal and $\sigma$ is the standard error of the regression equation.

Since monetary values are in log units, estimating the association between gambling stakes and the amount of credit repayment is effectively evaluating an elasticity. To be specific, a one per cent increase in credit repayments is associated with around 0.03 per cent higher total household gambling expenditure and also a 0.03 per cent higher gambling expenditure by adult individuals. As with the probability of any gambling, the elasticity of gambling stakes with respect to credit repayment is almost the same for all three levels of disaggregation. In general, the factors that were seen to determine the incidence of any gambling as reported in Table 1 are also seen to impact upon the amount of gambling as presented in Table 2. Thus, males who are older, white, less educated, in work and living in public housing are more likely to gamble, and to gamble more. Interestingly, the elasticity of gambling stakes is equally as large in terms of magnitude as the income elasticity at the

\footnotetext{
${ }^{9}$ There is also some information available in the EFS on credit card interest payments, and this is clearly an important source of credit for some households and individuals. Unfortunately, this data is reliably available only at the household level but not at the individual level, and hence we cannot include it in all three levels of aggregation examined here. However, for the household level equation, the results obtained when this additional source of credit is included show that household credit card interest payments have a similar impact on the probability of gambling as loan repayments, and the other coefficients are robust to its inclusion. Hence its omission would not appear to affect the substantive findings.
} 


\section{Variation in Gambling and use of Credit by Household Income}

A key question of interest is how the relationship between gambling and the use of credit as indicators of financial risk-taking varies across household income. In particular, do poorer households who may be more vulnerable to income uncertainty and volatility reveal rather different financial risk-taking behaviours? Tables 3 and 4 repeat the analysis in Tables 1 and 2 respectively, separately for households in the bottom quartile and top quartile of household income. For ease of comparison, the results for all households as obtained previously are also presented in the tables. Only the variables of

\footnotetext{
${ }^{10}$ As explained above, we can also include the amount of credit card interest payments in the household level equation as an additional credit repayment commitment. The results of this exercise reveal that, as with the probability of gambling, credit card interest repayments have a similar relationship to the level of gambling stakes as loan repayments, while the other coefficients are little affected by its omission/inclusion.

${ }^{11}$ Moreover, we are not suggesting a causal interpretation of the results presented, but rather the codetermination of gambling and credit repayments as indicators of financial risk taking by individuals and within households.
} 
immediate interest are reported, but in each case, the other covariates as in Table 1 and Table 2 are also included in each regression.

Table 3 reports the probit results for the incidence of any gambling and its association with any credit repayments. The first column repeats the results from Table 1 for all households, while the second and third columns report the results for the low income and high income households respectively. Results are reported for the three levels of aggregation as before in the three Panels of the table. The first point to note is that the relationship between gambling and income is non-linear. The overall effect measured across all households in Column 1 is estimated to be insignificantly different from zero, but this serves to obscure an important non-linear relationship. For low income households, there is a small but positive relationship between household income and the probability of gambling, but for high income households, there is a large and negative impact of increasing income on the probability of gambling. However, the positive association between gambling and the use of credit is approximately the same at all levels of household income, with the use of credit associated with a 4$5 \%$ higher probability of gambling.

Similar patterns are observed for heads of households as presented in Panel 2 and for individuals as in Panel 3, although for low income households, the positive relationship observed between household income and gambling propensity is smaller and not statistically significant. Individual income in high income households partly offsets the negative relationship between higher household income and the probability of gambling activity. The intra-household correlation (i.e. codetermination) in gambling is stronger for low income households than for high income households. Of most interest to this study, however, is that the positive relationship between gambling and the use of credit is around 4-5\% for all levels of aggregation and across all household income levels. This constancy in the estimated relationship suggests attitudes to financial risk-taking - at least with regard to the use of credit and gambling - are rather similar across household types.

Table 4 reports the tobit results by household income. Similar patterns are observed as in Table 3 above. The relationship between household income and gambling stakes is non-linear, and is positive for low income households (so gambling is a normal good) but negative for high income households (so gambling is an inferior good). But the elasticity of gambling stakes with respect to 


\section{Discussion and Conclusions}

Given the recent legislative changes relating to gambling in the UK together with innovations in the gambling industry promoting accessibility and the underlying trends towards increased gambling activity, it is surprising that there has been relatively little detailed research regarding gambling and its determinants in the UK. The various changes in the industry have attracted public debate however, fuelled by the existence of problem gambling and the increased prevalence of financial pressures at the household level. In order to understand the potential impact of these changes at the individual and household level, as well as on society more generally, we need to be better informed regarding which individuals engage in gambling, the intensity with which they gamble and, in particular, the degree to which gambling is associated with financial vulnerability. Our empirical findings suggest a positive

\footnotetext{
${ }^{12}$ We also investigated defining high and low income households by quartiles of equivalised household income rather than simply household income, in order to account for the income of households relative to their size. None of the results presented above are qualitatively affected by this alternative definition of 'poor' and 'rich' households. However, the differences in the intrahousehold correlations between low and high income households are even larger when using equivalised income to define relative household income, since the intrahousehold correlations are larger in poor households and smaller in rich households than those presented in Panel 3 in Tables 3 and 4.
} 
association between the propensity to engage in gambling activity and the use of credit at both the individual and the household level. In addition, we reveal a positive relationship between the amount spent on gambling and the level of credit repayments. Furthermore, we find evidence supporting a positive correlation between gambling activity across household members, thereby highlighting the possibility that financial vulnerability may be concentrated within particular types of household.

Focussing separately on poorer and richer households, we show that the relationship between gambling and household income is non-linear. However, the propensity of households and individuals to engage in gambling and their willingness to expose themselves to financial vulnerability through the use of credit appears to be little influenced or affected by household income. While richer households may be able to better protect themselves against financial uncertainty, those in poorer households are less able to do so. Given the current unease amongst policy makers regarding the levels of secured and unsecured debt at the household level, the similar attitude to financial risk-taking in terms of their propensity to gamble for given levels of indebtedness may be a cause for concern. It would certainly merit further investigation beyond the reduced form associations presented in this paper.

Acknowledgements: The EFS data are compiled by the Office for National Statistics and Department for Environment, Food and Rural Affairs (DEFRA) and distributed by the Economic and Social Data Service. They are Crown Copyright and reproduced with the permission of the Controller of HMSO and the Queen's Printer for Scotland. We would like to thank Aurora Ortiz for her research assistance and participants at the New Directions in Welfare conference at St Catherine's College, Oxford (June 2009) and an anonymous referee of this journal for their helpful comments on a previous version of this paper. The usual disclaimer applies. 


\section{REFERENCES}

Blaszczynski, A., Dumlao, V. and Lange, M. (1997) How much do you spend gambling? Ambiguities in survey questionnaire items, Journal of Gambling Studies, 13, 237-252.

Brown, S. and Taylor, K. B. (2008) Household debt and financial assets: evidence from Great Britain, Germany and the US, Journal of the Royal Statistical Society, Series A, 171, 615-634.

Brown, S., Garino, G. and Taylor, K. B. (2008) Mortgages and financial expectations: a household level analysis, Southern Economic Journal, 74, 857-878.

Clotfelter, C. and Cook, P. (1989) Selling hope. National Bureau for Economic Research, Harvard University Press, Cambridge, MA,

Fellner, G. and Maciejovsky, B. (2007) Risk attitude and market behaviour: Evidence from experimental asset markets, Journal of Economic Psychology, 28, 338-350.

Fisher, S. (1996) Gambling and pathological gambling among casino patrons. Report commissioned by the British Casino Industry, Plymouth, Centre for Research into the Social Impact of Gambling, University of Plymouth.

Gambling Commission (2008) Gambling industry statistics 2007/08, July.

GamCare (2003) GamCare care services report, National Association for Gambling Care, Educational Resources and Training, London.

Gropp, R., Scholz, J. K. and White, M. J. (1997) Personal bankruptcy and credit supply and demand, Quarterly Journal of Economics, 112, 217-51.

Ida, T. and Goto, R. (2009) Interdependency among addictive behaviours and time/risk preferences: discrete choice model analysis of smoking, drinking and gambling, Journal of Economic Psychology, 30, 608-621.

May, O., Tudela, M. and Young, G. (2004) British household indebtedness and financial stress: A household level picture, Bank of England Quarterly Bulletin. Winter, 2004. 
National Gambling Impact Study Commission (1999) Final report, Washington, DC, Government Printing Office, Available at http://govinfo.library.unt/ngisc/index.html (accessed 18 May 2009).

NORC (1999) Analysis of the casino survey, Report to the National Gambling Impact Study Commission, University of Chicago.

Office for National Statistics and Department for Environment, Food and Rural Affairs, Expenditure and Food Survey, 2007 [computer file]. UK Data Archive, Various, Colchester, Essex,.

Shepherd, R., Ghodse, H. and London, M. (1998) A pilot study examining gambling behaviour before and after the launch of the National Lottery and scratch cards in the UK, Addiction Research, $\mathbf{6}$, $5-12$

Sproston, K., Erens, B. and Orford, J. (2000) Gambling behaviour in Britain: results from the British Gambling Prevalence Survey, National Centre for Social Research, London.

Stinchfield, R. and Winters, K. C. (1998) Gambling and problem gambling among youths, Annals of the American Academy of Political and Social Science, 556, 172-185.

Tokunaga, H. (1993) The use and abuse of consumer credit: application of psychological theory and research, Journal of Economic Psychology, 14, 285-316.

Wardle H., Sproston, K., Orford, J., Erens, B., Griffiths, M., Constantine, R. And Pigott, S. (2007) British Gambling Prevalence Survey 2007, National Centre for Social Research, September, London.

Wärneryd, K.-E. (1996) Risk attitudes and risky behaviour, Journal of Economic Psychology, 17, 749-770.

Welte, J., Barnes, G., Wieczorek, W., Tidwell, M. and Parker, J. (2001) Alcohol and gambling pathology amongst US adults: prevalence, demographic patterns and comorbidity, Journal of Studies on Alcohol, 62, 706-712. 
Table 1. Probit analysis of the probability of gambling

\begin{tabular}{|c|c|c|c|c|c|c|c|c|c|}
\hline \multirow{3}{*}{$\begin{array}{l}\text { Specification A: } \\
\text { TOTAL CREDIT }\end{array}$} & \multicolumn{3}{|c|}{ Panel 1} & \multicolumn{3}{|c|}{ Panel 2} & \multicolumn{3}{|c|}{ Panel 3} \\
\hline & \multicolumn{3}{|c|}{ HOUSEHOLD LEVEL } & \multicolumn{3}{|c|}{ HEAD OF HOUSEHOLD } & \multicolumn{3}{|c|}{ INDIVIDUAL LEVEL } \\
\hline & M.E. & S.E & & M.E. & S.E & & M.E. & S.E & \\
\hline Whether any credit repayments\$ & 0.0510 & $(0.006)$ & $* * *$ & 0.0441 & $(0.006)$ & $* * *$ & 0.0521 & $(0.013)$ & $* * *$ \\
\hline Male\$ & 0.0148 & $(0.006)$ & $* *$ & 0.0238 & $(0.006)$ & $* * *$ & 0.0211 & $(0.011)$ & $* * *$ \\
\hline Age & 0.0240 & $(0.001)$ & $* * *$ & 0.0216 & $(0.001)$ & $* * *$ & 0.0251 & $(0.002)$ & $* * *$ \\
\hline Age squared/1000 & -0.2133 & $(0.012)$ & $* * *$ & -0.1934 & $(0.011)$ & $* * *$ & -0.2258 & $(0.025)$ & $* * *$ \\
\hline Age left full time education & -0.0270 & $(0.001)$ & $* * *$ & -0.0251 & $(0.001)$ & $* * *$ & -0.0197 & $(0.002)$ & $* * *$ \\
\hline Lone parent\$ & 0.0574 & $(0.012)$ & $* * *$ & 0.0532 & $(0.012)$ & $* * *$ & 0.0513 & $(0.032)$ & $* * *$ \\
\hline Non-white\$ & -0.1652 & $(0.011)$ & $* * *$ & -0.1030 & $(0.011)$ & $* * *$ & -0.1487 & $(0.029)$ & $* * *$ \\
\hline Log individual current income & - & - & & 0.0002 & $(0.002)$ & & 0.0065 & $(0.003)$ & $* * *$ \\
\hline Log household current income & -0.0012 & $(0.003)$ & & -0.0031 & $(0.003)$ & & -0.0168 & $(0.007)$ & $* * *$ \\
\hline Self-employed $\$$ & -0.0891 & $(0.009)$ & $* * *$ & -0.0779 & $(0.009)$ & $* * *$ & -0.0835 & $(0.022)$ & $* * *$ \\
\hline Unemployed\$ & -0.0282 & $(0.021)$ & & -0.0100 & $(0.020)$ & & -0.0253 & $(0.038)$ & $*$ \\
\hline Sick $\$$ & -0.0470 & $(0.017)$ & $* * *$ & -0.0562 & $(0.015)$ & $* * *$ & -0.0649 & $(0.031)$ & $* * *$ \\
\hline Retired\$ & 0.0224 & $(0.015)$ & & 0.0117 & $(0.015)$ & & 0.0057 & $(0.028)$ & \\
\hline Unoccupied\$ & -0.0419 & $(0.016)$ & $* * *$ & -0.0417 & $(0.015)$ & $* * *$ & -0.0626 & $(0.025)$ & $* * *$ \\
\hline Disability\$ & 0.0117 & $(0.012)$ & & -0.0069 & $(0.011)$ & & 0.0000 & $(0.026)$ & \\
\hline Number adults in household & 0.0532 & $(0.006)$ & $* * *$ & -0.0031 & $(0.006)$ & & -0.0012 & $(0.012)$ & \\
\hline Number children in household & -0.0135 & $(0.003)$ & $* * *$ & -0.0176 & $(0.003)$ & $* * *$ & -0.0144 & $(0.007)$ & $* * *$ \\
\hline Number workers in household & 0.0348 & $(0.006)$ & $* * *$ & 0.0103 & $(0.005)$ & $*$ & 0.0188 & $(0.012)$ & $* * *$ \\
\hline Workless household\$ & -0.0174 & $(0.013)$ & & -0.0177 & $(0.012)$ & & -0.0093 & $(0.025)$ & \\
\hline Cohabiting\$ & 0.0067 & $(0.010)$ & & 0.0240 & $(0.009)$ & $* *$ & 0.0274 & $(0.021)$ & $* * *$ \\
\hline Single\$ & -0.1086 & $(0.010)$ & $* * *$ & -0.0045 & $(0.010)$ & & -0.0055 & $(0.020)$ & \\
\hline Widowed\$ & -0.0924 & $(0.011)$ & $* * *$ & 0.0214 & $(0.011)$ & $* *$ & 0.0282 & $(0.025)$ & $* * *$ \\
\hline Separated/divorced\$ & -0.1067 & $(0.010)$ & $* * *$ & 0.0089 & $(0.010)$ & & 0.0029 & $(0.022)$ & \\
\hline Privately rent\$ & -0.0635 & $(0.011)$ & $* * *$ & -0.0713 & $(0.010)$ & $* * *$ & -0.0991 & $(0.026)$ & $* * *$ \\
\hline Owned on a mortgage\$ & -0.0215 & $(0.008)$ & $* * *$ & -0.0243 & $(0.008)$ & $* * *$ & -0.0539 & $(0.019)$ & $* * *$ \\
\hline Owned outright\$ & -0.0660 & $(0.008)$ & $* * *$ & -0.0615 & $(0.008)$ & $* * *$ & -0.0812 & $(0.019)$ & $* * *$ \\
\hline$\rho_{1}$ & & - & & - & - & & 0.2441 & $(0.008)$ & $* * *$ \\
\hline$\underline{\chi^{2}(43: 44: 44)[\mathrm{p} \text { value] }}$ & \multicolumn{3}{|c|}{$5236.1[\mathrm{p}=0.00]$} & \multicolumn{3}{|c|}{$2886.2[\mathrm{p}=0.00]$} & \multicolumn{3}{|c|}{$4174.1[\mathrm{p}=0.00]$} \\
\hline $\begin{array}{l}\text { Specification B: } \\
\text { TYPES OF CREDIT }\end{array}$ & M.E. & S.E & & M.E. & S.E & & M.E. & S.E & \\
\hline Whether any loan repayments\$ & 0.0430 & $(0.006)$ & $* * *$ & 0.0398 & $(0.006)$ & $* * *$ & 0.0417 & $(0.014)$ & $* * *$ \\
\hline Whether any HP repayments\$ & 0.0014 & $(0.009)$ & & 0.0089 & $(0.010)$ & & 0.0166 & $(0.024)$ & $*$ \\
\hline Whether any credit club rep's\$ & 0.0846 & $(0.011)$ & $* * *$ & 0.0821 & $(0.014)$ & $* * *$ & 0.0949 & $(0.030)$ & $* * *$ \\
\hline$\rho_{1}$ & - & - & & - & - & & 0.2435 & $(0.008)$ & $* * *$ \\
\hline$\underline{\chi^{2}(45: 46: 46)[\mathrm{p} \text { value] }}$ & \multicolumn{3}{|c|}{$5271.6[\mathrm{p}=0.00]$} & \multicolumn{3}{|c|}{$2905.1[\mathrm{p}=0.00]$} & \multicolumn{3}{|c|}{$4194.6[\mathrm{p}=0.00]$} \\
\hline Observations & \multicolumn{3}{|c|}{45,349} & \multicolumn{3}{|c|}{45,349} & \multicolumn{3}{|c|}{80,573} \\
\hline
\end{tabular}

Notes to Table 1:

1. Coefficients reported are marginal effects (M.E.) on the probability that the household (Panel 1), head of household (Panel 2) or adult individuals within the household (Panel 3) engages in any form of gambling activity. For dummy variables, denoted $\$$, the coefficient reported is for the discrete change of the dummy from 0 to 1 . Standard errors (S.E.) are in parentheses. $*, * *, * * *$ denotes statistical significance at the $10 \%, 5 \%$ and $1 \%$ levels respectively.

2. In the household level equation (Panel 1), the individual characteristics are those of the head of household. Reference categories are: female; head of household white; employee; no disability; at least one adult in work; married; local authority or housing association.

3. In Panel 3, $\rho_{1}$ is the proportion of the total variance accounted for by the intra-household variation in gambling propensity.

4. The $\chi^{2}$ test is a test for the joint significance of the explanatory variables.

5. The regression in Specification B which differentiates between different types of credit also includes all of the other independent variables reported in Specification A. Their coefficient estimates are little different from those in Specification A and so are not reported here but are available on request.

6. All regressions also include 6 calendar year dummy variables and 12 regional dummy variables. 
Table 2. Tobit analysis of gambling stakes

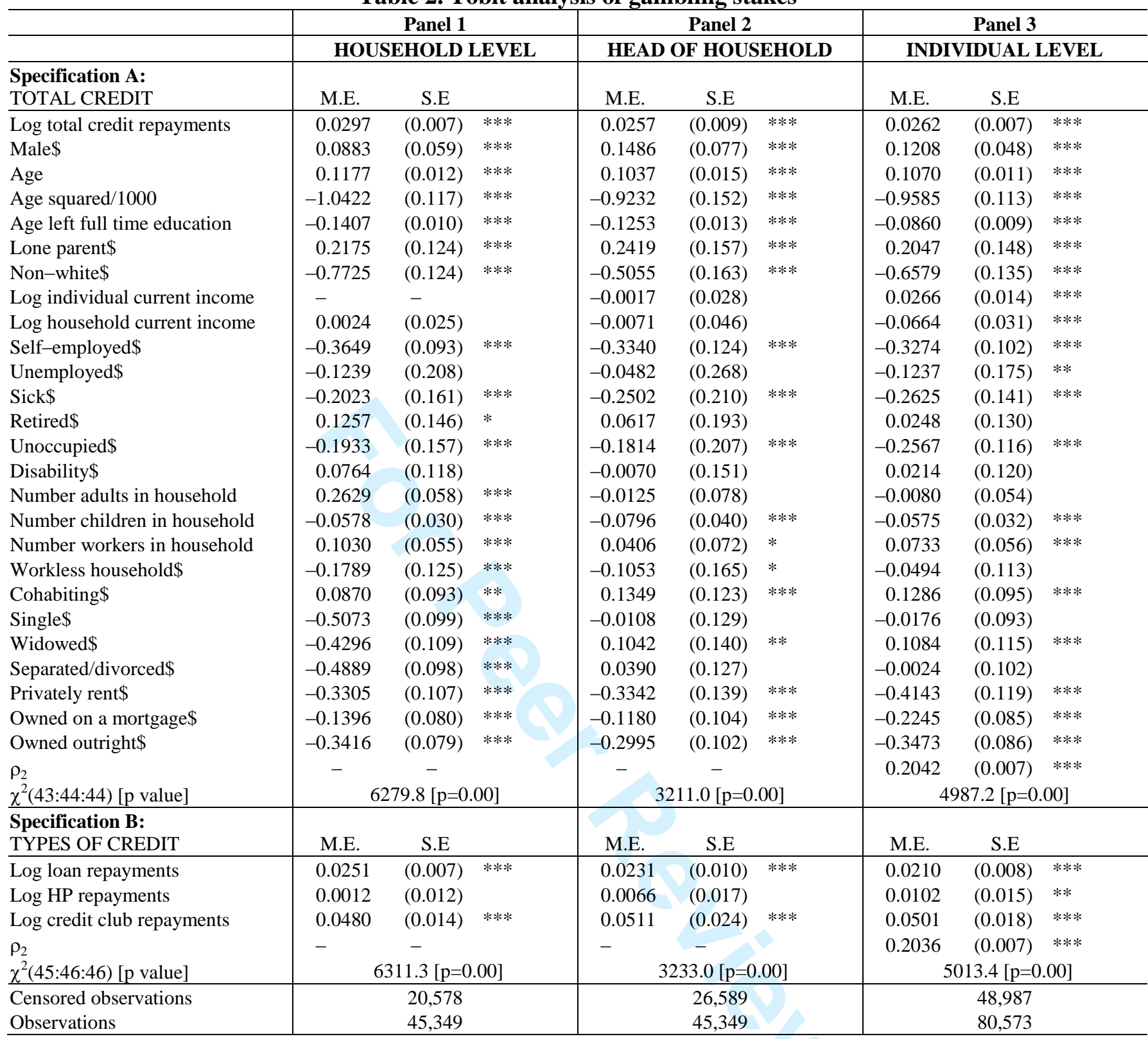

\section{Notes to Table 2:}

1. Coefficients reported are marginal effects (M.E.) on the gambling stakes of the household (Panel 1), head of household (Panel 2) or adult individuals within the household (Panel 3). For dummy variables, denoted \$, the coefficient reported is for the discrete change of the dummy from 0 to 1 . Standard errors (S.E.) are in parentheses. *,**,*** denotes statistical significance at the $10 \%, 5 \%$ and $1 \%$ levels respectively.

2. In the household level equation (Panel 1), the individual characteristics are those of the head of household. Reference categories are: female; head of household white; employee; no disability; at least one adult in work; married; local authority or housing association.

3. In Panel 3, $\rho_{2}$ is the proportion of the total variance accounted for by the intra-household variation in gambling stakes.

4. The $\chi^{2}$ test is a test for the joint significance of the explanatory variables.

5. The regression in Specification B which differentiates between different types of credit also includes all of the other independent variables reported in Specification A. Their coefficient estimates are little different from those in Specification A, and so are not reported here but are available on request.

6. All regressions also include 6 calendar year dummy variables and 12 regional dummy variables. 
Table 3. Probit analysis of the probability of gambling by household income

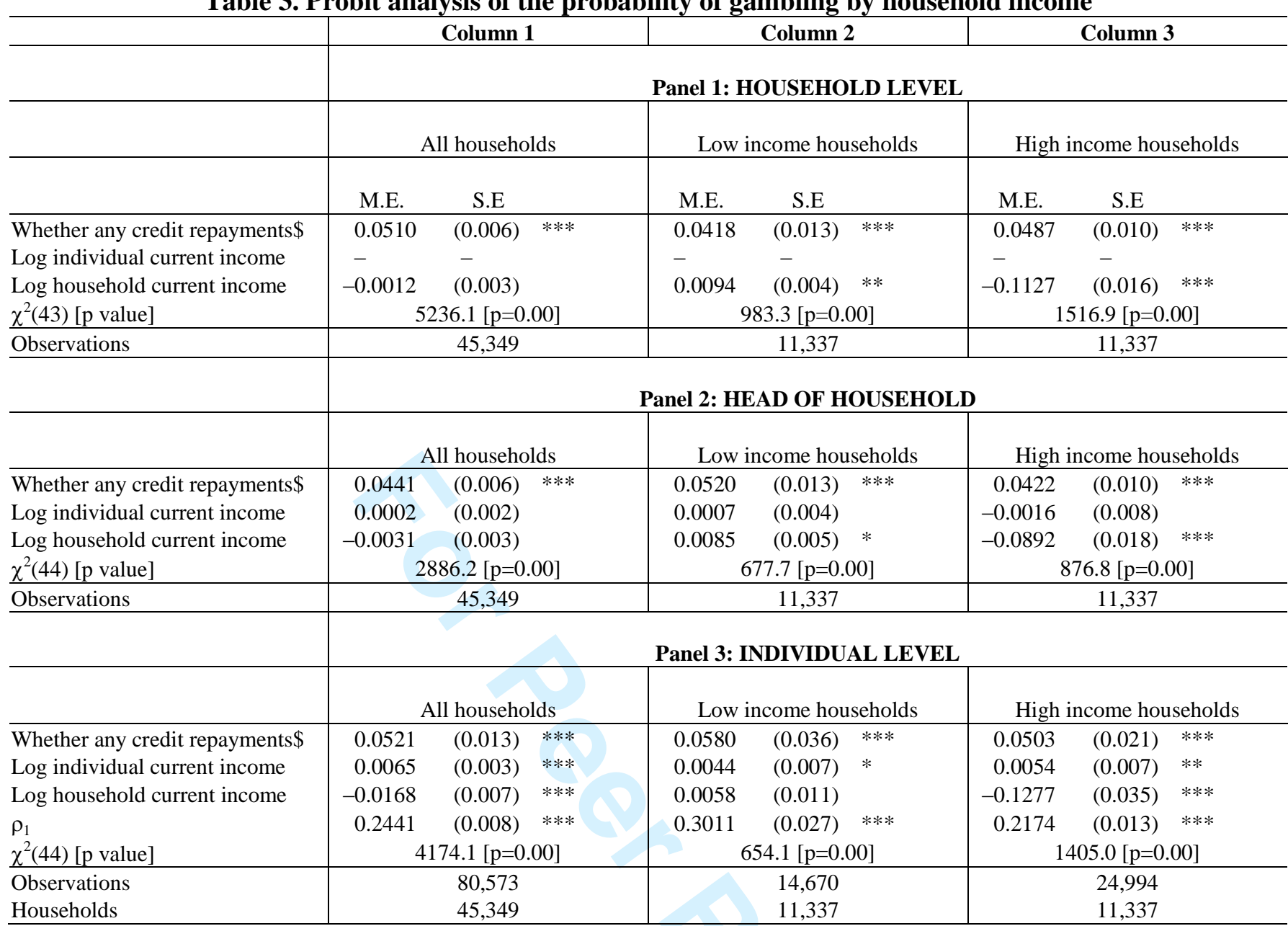

Notes to Table 3:

1. Coefficients reported are marginal effects (M.E.) on the probability that the household (Panel 1), head of household (Panel 2) or adult individuals within the household (Panel 3) engages in any form of gambling activity. For dummy variables, denoted $\$$, the coefficient reported is for the discrete change of the dummy from 0 to 1 . Standard errors (S.E.) are in parentheses. $*, * *, * * *$ denotes statistical significance at the $10 \%, 5 \%$ and $1 \%$ levels respectively.

2. In the household level equation (Panel 1), the individual characteristics are those of the head of household. Reference categories are: female; head of household white; employee; no disability; at least one adult in work; married; local authority or housing association.

3. In Panel 3, $\rho_{1}$ is the proportion of the total variance accounted for by the intra-household variation in gambling propensity.

4. The $\chi^{2}$ test is a test for the joint significance of the explanatory variables.

5. All regressions also include the control variable reported in Table 1, plus 6 calendar year dummy variables and 12 regional dummy variables.

6. Low/High income households are those that have a household income in the bottom/top quartile of the distribution of real household (equivalised) incomes. 
Table 4. Tobit analysis of gambling stakes by household income

\begin{tabular}{|c|c|c|c|c|c|c|}
\hline & \multicolumn{2}{|c|}{ Column 1} & Column 2 & \multicolumn{3}{|c|}{ Column 3} \\
\hline & \multicolumn{6}{|c|}{ Panel 1: HOUSEHOLD LEVEL } \\
\hline & \multicolumn{2}{|c|}{ All households } & Low income households & \multicolumn{3}{|c|}{ High income households } \\
\hline & M.E. & S.E & M.E. & M.E. & S.E & \\
\hline Log individual current income & - & - & - & - & - & \\
\hline Log household current income & 0.0024 & $(0.025)$ & $0.0384 \quad(0.042) \quad * *$ & -0.5244 & $(0.158)$ & $* * *$ \\
\hline$\chi^{2}(43)[\mathrm{p}$ value] & \multicolumn{2}{|c|}{$6279.8[\mathrm{p}=0.00]$} & $1125.9[\mathrm{p}=0.00]$ & \multicolumn{3}{|c|}{$1780.2[\mathrm{p}=0.00]$} \\
\hline Censored observations & \multirow{2}{*}{\multicolumn{2}{|c|}{$\begin{array}{l}20,578 \\
45,349 \\
\end{array}$}} & \multirow{2}{*}{$\begin{array}{c}6,074 \\
11,337 \\
\end{array}$} & \multirow{2}{*}{\multicolumn{3}{|c|}{$\begin{array}{c}5,001 \\
11,337 \\
\end{array}$}} \\
\hline Observations & & & & & & \\
\hline & \multicolumn{6}{|c|}{ Panel 2: HEAD OF HOUSEHOLD } \\
\hline & \multicolumn{2}{|c|}{ All households } & Low income households & \multicolumn{3}{|c|}{ High income households } \\
\hline Whether any credit repayments\$ & 0.0257 & $(0.009) \quad * * *$ & $0.0340 \quad(0.022) \quad * * *$ & 0.0230 & $(0.018)$ & $* * *$ \\
\hline Log individual current income & -0.0017 & $(0.028)$ & $(0.049)$ & -0.0070 & $(0.126)$ & \\
\hline Log household current income & -0.0071 & $(0.046)$ & $(0.064) *$ & -0.4169 & $(0.275)$ & $* * *$ \\
\hline$\chi^{2}(44)[\mathrm{p}$ value $]$ & \multicolumn{2}{|c|}{$3211.0[\mathrm{p}=0.00]$} & $752.8[\mathrm{p}=0.00]$ & \multicolumn{3}{|c|}{$939.4[\mathrm{p}=0.00]$} \\
\hline Censored observations & \multirow{2}{*}{\multicolumn{2}{|c|}{$\begin{array}{l}26,589 \\
45,349\end{array}$}} & \multirow{2}{*}{$\begin{array}{c}6,638 \\
11,337 \\
\end{array}$} & \multirow{2}{*}{\multicolumn{3}{|c|}{$\begin{array}{c}7,274 \\
11,337 \\
\end{array}$}} \\
\hline Observations & & & & & & \\
\hline & \multicolumn{6}{|c|}{ Panel 3: INDIVIDUAL LEVEL } \\
\hline & \multicolumn{2}{|c|}{ All households } & Low income households & \multicolumn{3}{|c|}{ High income households } \\
\hline Whether any credit repayments\$ & 0.0262 & $(0.007) \quad * * *$ & $(0.020) \quad * * *$ & 0.0253 & $(0.013)$ & $* * *$ \\
\hline Log individual current income & 0.0266 & $(0.014) \quad * * *$ & $(0.028) *$ & 0.0234 & $(0.037)$ & $* *$ \\
\hline$\underline{\chi^{2}(44)[\mathrm{p} \text { value }]}$ & \multicolumn{2}{|c|}{$4987.2[\mathrm{p}=0.00]$} & $908.0[\mathrm{p}=0.00]$ & \multicolumn{3}{|c|}{$1600.9[\mathrm{p}=0.00]$} \\
\hline Censored observations & \multirow{3}{*}{\multicolumn{2}{|c|}{$\begin{array}{l}48,987 \\
80,573 \\
45,349\end{array}$}} & \multirow{3}{*}{$\begin{array}{c}8,758 \\
14,670 \\
11,337\end{array}$} & & 16,441 & \\
\hline Observations & & & & & 24,994 & \\
\hline Households & & & & & 11,337 & \\
\hline
\end{tabular}

\section{Notes to Table 4:}

1. Coefficients reported are marginal effects (M.E.) on the gambling stakes of the household (Panel 1), head of household (Panel 2) or adult individuals within the household (Panel 3). For dummy variables, denoted \$, the coefficient reported is for the discrete change of the dummy from 0 to 1 . Standard errors (S.E.) are in parentheses. *, **, *** denotes statistical significance at the $10 \%, 5 \%$ and $1 \%$ levels respectively.

2. In the household level equation (Panel 1), the individual characteristics are those of the head of household.

3. In Panel 3, $\rho_{2}$ is the proportion of the total variance accounted for by the intra-household variation in gambling stakes.

4. The $\chi^{2}$ test is a test for the joint significance of the explanatory variables.

5. All regressions also include the control variable reported in Table 1, plus 6 calendar year dummy variables and 12 regional dummy variables.

6. Low/High income households are those that have a household income in the bottom/top quartile of the distribution of real household (equivalised) incomes. 